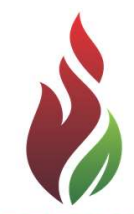

SUSTENERE

Publishing Corporation
ZRBADM

Journals Homepage:

www.sustenere.co/journals

\section{APLICAÇÃO DA METODOLOGIA DE BPM: O CASO DE UMA EMPRESA DE LOCAÇÃO DE VESTIDOS DE FESTA EM BELO HORIZONTE}

\section{RESUMO}

O Business Process Management (BPM) tem por objetivo a otimização de processos de negócio, a partir do mapeamento da situação atual, análise e remapeamento, de acordo com as considerações realizadas pelo analista. Sendo esta ferramenta bastante comum em grandes empresas, este trabalho busca explorar a sua aplicabilidade em uma empresa de pequeno porte que atua especificamente no segmento de serviços na indústria de vestuário, a fim de verificar se os benefícios do BPM decorrentes da otimização de processos são encontrados neste tipo de negócio. E neste contexto, a empresa é estudada segundo seus processos mais relevantes através da observação participante e da análise de documentos, resultando na aplicação de um ciclo de melhorias. Sendo uma empresa especializada na locação de vestidos de festa advindos de outras clientes, ação denominada "compartilhamento", os processos trabalhados versaram sobre a forma como estas peças são compartilhadas pelas clientes e a forma como ocorre a sua respectiva locação. O remapeamento destes processos gera uma nova visão, que busca realizar as mudanças decorrentes da identificação de possibilidades de melhorias e o reparo de seus pontos fracos. E após a implementação do BPM todas as melhorias aplicadas foram controladas através de indicadores de desempenho objetivando ampliar o controle dos processos de negócio. Embora sejam necessários outros estudos para validação da aplicabilidade do BPM em empresas de pequeno porte, foram evidenciados diversos benefícios para maximizar o processo de gestão e de comunicação da empresa foco deste trabalho.

PALAVRAS-CHAVES: Business Process Management; Otimização de Processos; Indústria de Vestuário.

\section{BPM METHODOLOGY APPLICATION: THE CASE OF A LEASING COMPANY OF PARTY DRESSES IN BELO HORIZONTE}

\section{ABSTRACT}

The Business Process Management (BPM) aims at the optimization of business processes, from mapping the current situation, analysis and remapping, according to the considerations made by the analyst. Since this is quite common tool in large companies, this paper seeks to explore their applicability in a small business that operates specifically in the services segment in the apparel industry in order to verify that the benefits of BPM resulting from process optimization are found this type of business. And in this context, the company is studied according to their most relevant processes through participant observation and document analysis, resulting in the application of an improvement cycle. As a company specializing in the rental of party dresses coming from other clients, called the action "sharing", the process worked were about how these parts are shared by clients and how is their respective lease. The remapping of these processes generates a new vision, which seeks to make the changes resulting from the identification of improvement opportunities and the repair of their weaknesses. And after the implementation of BPM all applied improvements were controlled through performance indicators aiming to extend the control of business processes. Although further studies to validate the applicability of BPM in small businesses, it was highlighted several benefits to maximize the management process and the focus of this paper company communication.

KEYWORDS: Business Process Management; Process Optimization; Apparel Industry.
Revista Brasileira de

Administração Científica,

Aquidabã, v.6, n.2, Jul, Ago, Set,

Out, Nov, Dez 2015.

ISSN 2179-684X

SECTION: Articles

TOPIC: Estratégia e

Competitividade

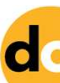

DOI: 10.6008/SPC2179-684X.2015.002.0007

Juliana Elisei Almada

Centro Federal de Educação Tecnológica de Minas Gerais, Brasil

http://lattes.cnpq.br/0115719732444914 jusoad@hotmail.com

Uajará Pessoa Araújo

Centro Federal de Educação Tecnológica de Minas Gerais, Brasil

http://lattes.cnpq.br/3898285928077336 uajara@yahoo.com.br

Enderson Fabian de Carvalho

Centro Federal de Educação Tecnológica de Minas Gerais, Brasil

http://lattes.cnpq.br/4725721513661037

endersonfabian@gmail.com

Paulo Fernandes Sanches Junior Centro Federal de Educação Tecnológica de Minas Gerais, Brasil

http://lattes.cnpq.br/3148405797604378 psanchesjr@gmail.com

Received: 06/08/2015

Approved: 04/11/2015

Reviewed anonymously in the process of blind peer.

Referencing this:

ALMADA, J. E.; ARAUJO, U. P.; CARVALHO, E. F. SANCHES JUNIOR, P. F. Aplicação da metodologia de BPM: o caso de uma empresa de locação de vestidos de festa em Belo Horizonte. Revista Brasileira de Administração Científica, Aquidabã, v.6, n.2, p.94-116,

2015. DOI: http://dx.doi.org/10.6008/SPC2179 $684 X .2015 .002 .0007$ 


\section{INTRODUÇÃO}

A administração de empresas é amparada por diferentes ferramentas que buscam auxiliar os objetivos estratégicos dos gestores. Com o desenvolvimento de novas tecnologias, amadurecimento das empresas e diferenciação dos clientes nos últimos anos, fez-se necessária a adequação das ferramentas ao novo perfil de negócios. As ferramentas clássicas de administração, como reengenharia e automação, buscavam, em geral, o corte de custos e a agilidade. Em contrapartida, hoje as empresas buscam criar uma experiência diferenciada para o cliente, aumentar a geração de receitas e a inovação em negócios. As novas tecnologias e a disponibilização crescente de informações tornaram o cliente mais exigente e esta nova métrica faz-se mais adequada para empresas que pretendem alcançar posição destacada no mercado.

Neste contexto tem-se o desenvolvimento do mapeamento e controle de processos. Iniciado no final da década de 80 , esta prática buscou identificar melhorias na organização e, desde então, tem se transformado em um importante alicerce da gestão empresarial. Dentre as ferramentas desenvolvidas neste sentido, o Gerenciamento de Processos de Negócio ou Business Process Management (BPM) é uma abordagem elaborada para a identificação, desenho, execução e documentação dos processos de negócios. Com isso espera-se criar formas de medição e monitoramento dos processos a fim de se alcançar melhorias que reflitam diretamente na atuação e estratégia das empresas.

Tratando-se de uma ferramenta relativamente nova, é importante a verificação de sua aplicabilidade em setores diversos. Deve-se considerar que apesar de bastante difundida, ainda existem diversas lacunas no estudo do BPM e de sua aplicação prática em alguns segmentos. Neste sentido esta pesquisa busca verificar a aplicabilidade desta metodologia através de sua implementação em uma organização no setor de serviços, especificamente em uma empresa focada em inovação, o que significa contar com processos inovadores, susceptíveis a erros que podem comprometer a viabilidade do negócio. A empresa analisada é nova no mercado e tem como foco a implementação de um novo conceito de compartilhamento de produtos entre os próprios clientes, especificamente no ramo de vestuário feminino e da moda. Buscou-se então verificar o potencial que a metodologia de BPM possui na melhoria dos processos desta empresa e, consequentemente, na melhoria de gestão da organização.

Os estudos que demonstram a aplicação prática da ferramenta são geralmente pautados em grandes empresas, como multinacionais, importantes órgãos públicos ou empresas que já desenvolvem seus métodos e processos há mais tempo, garantindo melhor conhecimento do negócio, conforme será apresentado mais adiante. Neste sentido vale ressaltar que esta pesquisa pretende analisar a aplicação prática da ferramenta em uma empresa recém-iniciada e classificada como PME - Pequena e Média Empresa. 


\section{Gestão Funcional X Gestão Por Processos}

Há diferentes formas de se estabelecer estruturas organizacionais, adequadas aos mais diversos tipos de gestão empresarial. As empresas costumam, tradicionalmente, agrupar departamentos considerando-se funções da empresa, em decorrência de uma visão simplificada de divisão do trabalho. Este tipo de divisão facilita quando se considera os diferentes departamentos da empresa, com suas necessidades específicas, como pessoal especializado, recursos, forma de trabalho, dentre outros. Entretanto, os processos devem ser considerados tendo em vista que são eles que realmente produzem os resultados da empresa. Paim (2001) afirma que a gestão tradicionalmente funcional pode ser mudada para uma gestão orientada por processos, no sentido da agregação de valor que ocorre horizontalmente nas organizações. $\mathrm{Na}$ Figura 1 é possível perceber como se dá as diferenças entre as alternativas de estruturas organizacionais passando de uma visão departamentalizada, em que as áreas funcionais são priorizadas na gestão e caminhando gradualmente para uma visão horizontal, com foco no resultado de processos gerenciais.

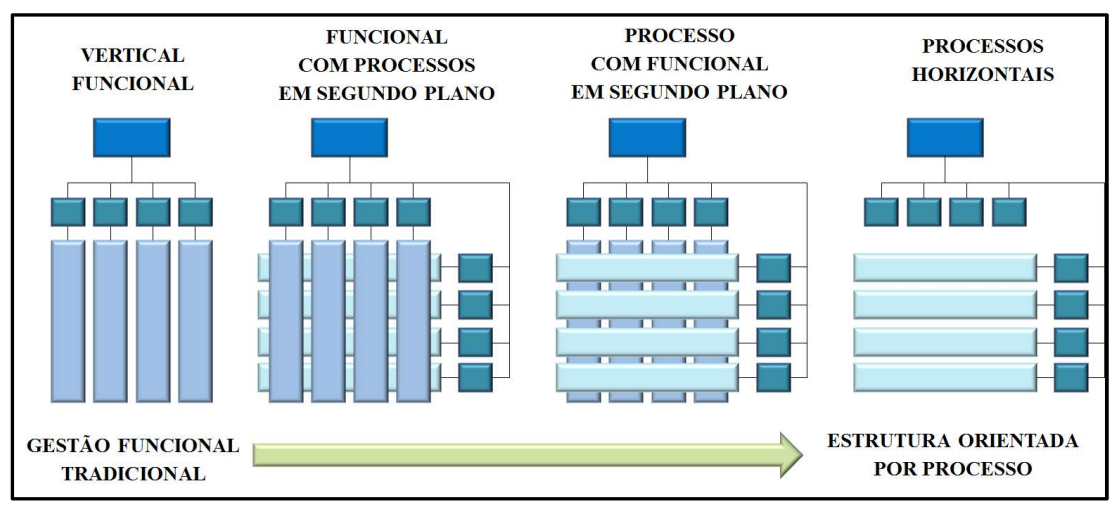

Figura 1: Alternativas de Estruturas Organizacionais.

Os processos geralmente atravessam barreiras departamentais, cruzando a estrutura organizacional. Em uma empresa que se organiza de forma departamentalizada, isto é, focada na gestão vertical, podem existir importantes processos sem o devido acompanhamento. Isso ocorre porque na visão departamentalizada, cada setor preocupa-se com seus próprios resultados, entretanto, existem processos, geralmente sobrepostos em mais de um departamento, que efetivamente garantem criação de valor para o cliente e que não são devidamente acompanhados. Na gestão por processos o acompanhamento ocorre de forma interdepartamental, considerando-se o resultado esperado do processo e não a divisão funcional da empresa. Para Hammer (1998), mudar a estrutura funcional da empresa para uma estrutura por processos implica definir a responsabilidade pelo andamento do processo, minimizar as transferências (para reduzir esperas, erros e fronteiras), maximizar o agrupamento de atividades e diminuir o gasto de energia (reunir as partes da empresa em menor número de locais ou empregar maciçamente os recursos de tecnologia de informação para diminuir gastos com transporte, armazenagem e deslocamento). 
Um típico departamento de contabilidade enfoca tarefas associadas ao monitoramento, medição e reporte de operações financeiras dentro da organização. O trabalho é contínuo e permanente. Os processos de negócio, todavia, focam transações ponta-a-ponta para agregar valor ao cliente. Esses processos ponta-a-ponta frequentemente incluem tarefas relacionadas à satisfação dos clientes através do cumprimento dos seus pedidos. As funções do departamento de contabilidade suportam esses processos de negócio através da execução de tarefas específicas. Entretanto, esse departamento não é tipicamente responsável pelo trabalho ponta-a-ponta associado ao macro processo de negócio (ABPMP, 2009, p.33).

Assim o diferencial entre as duas abordagens refere-se ao fato que as barreiras interdepartamentais dificultam a otimização do trabalho e a gestão do fluxo de informações. Desta forma, na visão vertical, o enfoque se dá na gestão dos recursos, já no gerenciamento de processos a abordagem utilizada possui foco no cliente.

\section{REVISÃO TEÓRICA}

Para ser compreendida na esfera de um negócio, a aplicação de uma metodologia baseada em processos precisa primeiramente ser contextualizada. Inicia-se então com a definição do termo negócio. Para Cruz (2010), negócio é a reunião de três elementos: pessoas, processos e tecnologias da informação, com a finalidade de atender a expectativa do cliente. Pode-se dizer também que a definição do negócio de uma organização é a definição de quais produtos e serviços à organização pretende fornecer, para quais mercados e quais clientes, segundo Maximiano (2005). Percebe-se que o negócio é o fator que liga a empresa em si ao cliente, variando os meios para se alcançar o cliente de acordo com cada organização.

Neste contexto pode-se considerar que o processo empresarial é a base do negócio e sustenta a forma como a organização trabalha. De acordo com Cruz (2010), processo de negócio é o conjunto de atividades que tem por objetivo transformar insumos (entradas), adicionando-lhes valor por meio de procedimentos, em bens ou serviços (saídas) que serão entregues e devem atender aos clientes. Desta forma fica claro perceber a importância para a organização analisar, gerenciar e promover melhores fluxos de trabalho e processos que garantam com maior objetividade a necessidade da empresa. Trabalhar estes processos passa então a ser um fator chave na gestão do negócio. De fato, Gonçalves (2000) afirma que a organização se apresenta como uma rede de processos e Johansson et al. (1995) afirmam que uma organização é tão efetiva quanto forem os seus processos, pois eles são responsáveis pelo que será ofertado ao cliente. É de grande importância o entendimento do conceito de processo. De acordo com Davenport (1994), processo é uma ordenação específica das atividades no tempo e no espaço, com começo e fim identificados.

Um processo é um conjunto definido de atividades ou comportamentos executados por humanos ou máquinas para alcançar uma ou mais metas. Os processos são disparados por eventos específicos e apresentam um ou mais resultados que podem conduzir ao término do 
processo ou a transferência de controle para outro processo. Processos são compostos por várias tarefas ou atividades inter-relacionadas que solucionam uma questão específica. No contexto do gerenciamento de processos de negócio, um "processo de negócio" definido como um trabalho ponta-a-ponta que entrega valor aos clientes. A noção de trabalho ponta-a-ponta é chave, pois envolve todo o trabalho cruzando limites funcionais necessários para entregar valor aos clientes (ABPMP, 2009, p.30).

Especificamente em uma empresa de serviços, como no caso da empresa a ser pesquisada, o processo facilita a visão do que está sendo entregue para o cliente. Na visão de Gonçalves (2000), nas empresas de serviços o conceito de processo é de fundamental importância, uma vez que a sequência de atividades nem sempre é visível, nem pelo cliente, nem pelas pessoas que realizam essas atividades.

Neste sentido a gestão por processos é atualmente empregada nas diversas áreas da administração tais como qualidade, implantação de sistemas de informação e outras (Cruz, 2010). Isso ocorre porque, de acordo com Gonçalves (2000), considerar a empresa a partir de seus processos facilita a identificação de falhas e defeitos nas operações, a identificação de processos essenciais e a restauração/reestruturação dos processos para obter um desempenho efetivo, eliminando falhas e diminuindo custos, isso incluindo a redução de desperdício e de retrabalho.

\section{Gerenciamento de Processos de Negócio}

Gerenciamento de processos de negócio é uma disciplina de gerenciamento e um conjunto de tecnologias que provê suporte ao gerenciamento por processo, de acordo com ABPMP (2009). Espera-se que, para sua aplicação, haja um ambiente colaborativo e culturalmente sustentável na organização. Deve ser suportado por métodos e ferramentas adequados, que garantam a aplicação da metodologia. Sendo uma disciplina em constante evolução, a tendência atual do BPM concentra-se em processos organizacionais e multifuncionais que agregam valor aos clientes (ABPMP, 2009).

Forster citado por Netto (2005) afirma que quando uma organização consegue coordenar o ciclo completo dos processos de seu negócio, ela consegue visualizar as ligações entre pessoas, tecnologia e processos propriamente ditos, otimizando o compartilhamento de dados informações e recursos, bem como facilitando a relação entre funcionários, parceiros, fornecedores e clientes. Os processos de negócio definem como as organizações executam o trabalho para entregar valor para seus clientes. O gerenciamento determinado desses processos cria práticas organizacionais mais fortes que conduzem a processos mais eficazes, a uma maior eficiência, mais agilidade e, finalmente, a um retorno mais alto dos investimentos das partes interessadas (ABPMP, 2009). Esta melhoria organizacional é sustentada por modelos de negócio, definidos de acordo com as ferramentas do BPM. De acordo com Pidd (1999), um modelo pode ser entendido como uma 
representação explícita e externa de parte da realidade vista por pessoas que desejam usar o modelo para: entender, mudar, gerenciar e controlar esta parte da realidade de alguma forma.

Neste contexto, o presente estudo visa aplicar a metodologia através do ciclo de vida do Gerenciamento de Processos de Negócio. Para a ABPMP (2009), a prática gerencial de BPM pode ser caracterizada como um ciclo de vida contínuo que inclui: planejamento; análise; desenho e modelagem; implantação; monitoramento e controle; e (refinamento). O planejamento se dá com o desenvolvimento de um plano e uma estratégia dirigida a processos para a organização. De acordo com a ABPMP (2009), o plano inicia por um entendimento das estratégias e metas da organização desenhadas para assegurar uma proposição de valor atrativa para clientes. O plano fornece uma estrutura e o direcionamento para gerenciamento contínuo de processos centrados no cliente. Nesta fase também se deve identificar papéis e responsabilidades organizacionais, patrocínio executivo, metas, expectativas de medições de desempenho e metodologias.

Já a análise visa entender os atuais processos organizacionais no contexto das metas e objetivos desejados. Desta forma a análise busca assimilar informações oriundas de planos estratégicos, modelos de processo, medições de desempenho, mudanças no ambiente externo e outros fatores, a fim de entender completamente os processos de negócio no escopo da organização como um todo. É um momento de coleta de informações e entendimento mais aprofundado da organização (ABPMP, 2009).

No âmbito do desenho e modelagem de processos podem-se destacar as variedades encontradas de acordo com o grau de abrangência do processo, sendo definido através de diferentes conceituações: Macroprocesso: processo que geralmente envolve mais de uma função da organização, e sua operação tem impacto significativo no modo como a organização funciona; Processo: é um conjunto de atividades sequenciais (conectadas), relacionadas e lógicas que tomam um input com um fornecedor, acrescentam valor a este e produzem um output para um consumidor; Subprocesso: é a parte que inter-relacionada de forma lógica com outro subprocesso, realiza um objetivo específico em apoio ao macroprocesso e contribui para a missão deste; Atividades: são coisas que ocorrem dentro do processo ou subprocesso. São geralmente desempenhadas por uma unidade (pessoa ou departamento) para produzir um resultado particular. Elas constituem a maior parte dos fluxogramas; Tarefa: é a parte específica do trabalho, ou melhor, o menor micro enfoque do processo, podendo ser um único elemento e/ou subconjunto de uma atividade. Geralmente, está relacionado à como um item desempenha uma incumbência específica. (PORCIDES, 2012)

Geralmente as organizações conhecem seus processos, entretanto, pode não haver a sua formalização e documentação. Nesta etapa o processo torna-se palpável e possível de ser trabalhado e transmitido entre colaboradores. Isto é realizado através de fluxogramas, que são ferramentas intermediárias no gerenciamento de processos. É importante ressaltar que a quantidade de fluxogramas documentados não representa resultado, mas sim o seu desenvolvimento e aplicação de acordo com a disciplina de BPM. O desenho e modelagem de 
processo retratam de forma intencional e cuidadosa a forma como o trabalho ocorre. O desenho define o que a organização quer que o processo seja e responde questões como: o quê, quando, onde, quem e como o trabalho ponta-a-ponta é realizado. Em um ciclo de vida iterativo de BPM, atividades iniciais de desenho podem focar na padronização ou automação de atividades atualmente realizadas ad-hoc, enquanto atividades de desenho mais maduras podem focar no redesenho ou transformação radical do processo, ou melhorias incrementais desenhadas para otimização (ABPMP, 2009).

Implantação é a realização do desenho do processo, aprovado previamente nas etapas anteriores, através de procedimentos e fluxo de trabalhos documentados, testados e operacionalizados. Inclui a implementação de políticas e procedimentos novos ou revisados. De acordo com Nogueira (2012), nesta fase realiza-se também o ajuste das especificações criadas e aprovadas na análise e modelagem/ desenho dos processos. Na etapa de monitoramento e controle são providas informações-chave no desempenho dos processos através de métricas relacionadas às metas e ao valor para a organização, podendo resultar em atividades de melhoria, redesenho ou reengenharia, de acordo com ABPMP (2009). As métricas a serem utilizadas podem referir-se ao tempo, isto é, a duração do processo como um todo ou de parte do processo; custo, que é uma métrica monetária associada ao processo; capacidade, sendo esta montante ou volume de uma saída do processo e a qualidade, geralmente expressa em percentual ou valor esperado do processo, em termos como satisfação, erro, variação ou taxa de defeito.

Vale ressaltar que, de acordo com ABPMP (2009), os Indicadores de Desempenho, utilizados no controle e monitoramento dos processos, devem também obedecer a certos parâmetros, devendo ser: Específicos: claramente definidos e compreendidos; Relevantes: devem agregar valor ao negócio; Alcançáveis: passíveis de alcançarem as metas propostas; Mensuráveis: qualificáveis e passíveis de documentação; Atrelado a prazo: ao se definir uma meta, deve ser possível mensurar um prazo estimado para alcançá-la.

Por fim, o refinamento é a etapa que compreende o tratamento de aspectos de ajustes e melhorias pós-implementação de processos com base nos indicadores e informações-chave de desempenho. Nesta etapa admite-se a implantação do resultado da análise iterativa e do ciclo de desenhos, orientado para a melhoria contínua e otimização do processo, conforme explicitado por Nogueira (2012). Além do entendimento do conceito e da forma como a literatura propõe a utilização da modelagem de negócio, é importante entender a forma como esta é aplicada no contexto de diferentes tipos de organizações. Neste sentido, pretende-se expor estudos variados que utilizaram desta ferramenta, dando enfoque para a forma como isto foi feito e o resultado obtido. O Quadro 1 demonstra o resultado desta pesquisa. Como se pode ver, o estudo de BPM retoma diversos conceitos e entendimentos da metodologia, existindo, entretanto, muito espaço para uma aplicação prática da disciplina, inclusive no que esta pesquisa se propõe: empresa recém-criada de serviços do ramo da moda. 
QUADRO 1: Trabalhos que demonstram a aplicabilidade da ferramenta BPM.

\begin{tabular}{|c|c|c|c|}
\hline Artigo & Autor & Método & Considerações dos autores \\
\hline $\begin{array}{l}\text { Assessment model for } \\
\text { organizational business } \\
\text { process maturity with a } \\
\text { focus on BPM governance } \\
\text { practices. }\end{array}$ & $\begin{array}{l}\text { Boer et } \\
\text { al.(2015). }\end{array}$ & $\begin{array}{l}\text { Estudo de caso que propõe um modelo de avaliação de } \\
\text { maturidade para a gestão de processos com foco em } \\
\text { práticas de governança gestão de processos de } \\
\text { negócios (BPM). }\end{array}$ & $\begin{array}{l}\text { O modelo permitiu diagnosticar situação atual } \\
\text { das organizações em termos de gestão de } \\
\text { processos e forneceu uma avaliação preliminar } \\
\text { dos próximos passos na evolução da maturidade } \\
\text { de cada um dos fatores analisados. }\end{array}$ \\
\hline $\begin{array}{l}\text { Ten principles of good } \\
\text { business process } \\
\text { management. }\end{array}$ & $\begin{array}{l}\text { Brocke et al. } \\
(2014) .\end{array}$ & $\begin{array}{l}\text { Propõem um conjunto de dez princípios que } \\
\text { caracterizam a utilização do BPM como uma prática } \\
\text { organizacional bem sucedida. }\end{array}$ & $\begin{array}{l}\text { Os dez princípios foram considerados como um } \\
\text { importante ponto de partida para moldar a } \\
\text { aplicação do BPM tanto no meio acadêmico } \\
\text { como na prática organizacional. Cada princípio } \\
\text { oferece uma estrutura conceitual para melhorar a } \\
\text { aplicação do BPM bem como oferecer um roteiro } \\
\text { para futuras pesquisas acerca do tema. }\end{array}$ \\
\hline $\begin{array}{l}\text { Gestão de processos } \\
\text { aplicada à realização de } \\
\text { convênios internacionais } \\
\text { bilaterais em uma } \\
\text { instituição de ensino } \\
\text { superior pública brasileira. }\end{array}$ & $\begin{array}{l}\text { Mückenberger } \\
\text { et al. (2013) }\end{array}$ & $\begin{array}{l}\text { Propõe abordagem do BPM no âmbito de uma } \\
\text { instituição de ensino superior pública brasileira, } \\
\text { especificamente no processo de realização de } \\
\text { convênios bilaterais internacionais da escola. O } \\
\text { processo modelado em sua forma vigente e, a partir da } \\
\text { análise desse modelo, foram propostas melhorias, um } \\
\text { novo modelo e indicadores de desempenho. }\end{array}$ & $\begin{array}{l}\text { Os autores apontam para a simplificação e } \\
\text { melhoria do processo com redução do seu } \\
\text { tempo de execução, sugerindo a ampliação da } \\
\text { aplicabilidade do BPM em outros aspectos da } \\
\text { internacionalização da instituição de ensino. }\end{array}$ \\
\hline $\begin{array}{l}\text { Gestão de Processos: uma } \\
\text { Metodologia Redesenhada } \\
\text { para a Busca de Maior } \\
\text { Eficiência e Eficácia } \\
\text { Organizacional. }\end{array}$ & Pradella (2013) & $\begin{array}{l}\text { Empresa que atua no ramo de serviços educacionais. A } \\
\text { partir de necessidade de melhorias observadas na } \\
\text { instituição, é levantada a cadeia de valor da empresa, } \\
\text { com análise dos pontos de melhoria e utilização de } \\
\text { simulação de cenários através de software específico. }\end{array}$ & $\begin{array}{l}\text { Considera o aperfeiçoando do detalhamento do } \\
\text { passo a passo dos processos mais relevantes à } \\
\text { cadeia de valor da instituição e maior qualidade, } \\
\text { padronização e agilidade após a utilização da } \\
\text { ferramenta. }\end{array}$ \\
\hline $\begin{array}{l}\text { Increasing process } \\
\text { orientation with business } \\
\text { process management: } \\
\text { Critical practices. }\end{array}$ & $\begin{array}{l}\text { Skrinjar e } \\
\text { Trkman (2013). }\end{array}$ & $\begin{array}{l}\text { Estudo de caso para identificar os fatores críticos de } \\
\text { sucesso que contribuem para maximizar o nível de } \\
\text { maturidade do BPM. }\end{array}$ & $\begin{array}{l}\text { Ajustes entre as tarefas e os recursos } \\
\text { tecnológicos disponíveis contribuem para } \\
\text { maximizar o nível de maturidade em BPM. } \\
\text { Entretanto, as práticas críticas devem ser } \\
\text { utilizadas como indicadores e não como } \\
\text { sugestões normativas, haja vista que os fatores } \\
\text { críticos identificados podem não se aplicar a } \\
\text { todos os tipos de segmento de mercado. }\end{array}$ \\
\hline $\begin{array}{l}\text { Melhorias em processos } \\
\text { com impacto na eficiência } \\
\text { operacional: um estudo } \\
\text { ambientado em um } \\
\text { laboratório de análises } \\
\text { clínicas. }\end{array}$ & $\begin{array}{l}\text { Millan e } \\
\text { Versetti (2012) }\end{array}$ & $\begin{array}{l}\text { Foram analisados os macroprocessos do Laboratório e } \\
\text { identificadas oportunidades de melhoria. Além disso, foi } \\
\text { proposta a reestruturação dos macroprocessos } \\
\text { analisados, apresentando os recursos necessários à } \\
\text { implementação da proposta, bem como indicadores de } \\
\text { desempenho e suas respectivas metas. }\end{array}$ & $\begin{array}{l}\text { Considera que o mapeamento em prestadoras } \\
\text { de serviço da área da saúde possui apelo } \\
\text { considerável devido intangibilidade do serviço e } \\
\text { alto nível de incerteza. A análise dos processos } \\
\text { se tornou mais precisa permitindo melhora do } \\
\text { desempenho organizacional. }\end{array}$ \\
\hline $\begin{array}{l}\text { Proposta de instrumento } \\
\text { para medição do estado } \\
\text { atual da gestão por } \\
\text { processos nas } \\
\text { organizações brasileiras. }\end{array}$ & $\begin{array}{l}\text { Nogueira } \\
\text { (2012) }\end{array}$ & $\begin{array}{l}\text { Elaborar instrumento para verificar estado atual da } \\
\text { gestão por processos em organizações brasileiras, no } \\
\text { sentido de apontar lacunas e oportunidades de } \\
\text { melhorias para a utilização do BPM por outras } \\
\text { organizações. Não é utilizado estudo de caso para } \\
\text { validação. }\end{array}$ & $\begin{array}{l}\text { O instrumento foi elaborado considerando os } \\
\text { critérios de validade e confiabilidade. }\end{array}$ \\
\hline $\begin{array}{l}\text { Implantação de sistema } \\
\text { BPMS para a gestão por } \\
\text { processos: uma análise } \\
\text { crítica. }\end{array}$ & Carrara (2011) & $\begin{array}{l}\text { Estudo da implementação de sistema utilizando } \\
\text { ferramenta BPM em instituição de ensino de médio } \\
\text { porte através de estudo de caso. Foram sugeridas } \\
\text { proposições gerais sobre o assunto, sendo discutidas e } \\
\text { criticadas através do estudo de caso. }\end{array}$ & $\begin{array}{l}\text { As proposições não se confirmaram totalmente, } \\
\text { apontando para um distanciamento entre teoria e } \\
\text { prática. Aponta também para maior envolvimento } \\
\text { do usuário do negócio na implantação do } \\
\text { sistema. }\end{array}$ \\
\hline $\begin{array}{l}\text { From process logic to } \\
\text { business logic-A } \\
\text { cognitive approach to } \\
\text { business process } \\
\text { management. }\end{array}$ & $\begin{array}{l}\text { Wang e Wang } \\
\text { (2006). }\end{array}$ & $\begin{array}{l}\text { Uma abordagem cognitiva é proposta para ajudar a } \\
\text { gerenciar as atividades de negócios complexos, com } \\
\text { base em sensibilização contínua de situações e } \\
\text { decisões em tempo real sobre as atividades. }\end{array}$ & $\begin{array}{l}\text { Considerando-se o processo complexo em um } \\
\text { ambiente dinâmico com atividades não } \\
\text { estruturadas e volumes de interações, esta } \\
\text { abordagem foi concebida para assegurar a } \\
\text { flexibilidade e adaptabilidade na evolução do } \\
\text { processo de contínua percepção de todo o } \\
\text { ambiente e em tempo real e controle do } \\
\text { processo de decisão. }\end{array}$ \\
\hline $\begin{array}{l}\text { Managing context in } \\
\text { business process } \\
\text { management systems. }\end{array}$ & $\begin{array}{l}\text { Ramesth et al. } \\
\text { (2005). }\end{array}$ & $\begin{array}{l}\text { Identificação de requisitos para um processo de } \\
\text { negócio capaz de gerenciar um sistema de gestão } \\
\text { baseado em conhecimento. }\end{array}$ & $\begin{array}{l}\text { A falta de conhecimento na concepção de } \\
\text { processos de negócios compromete a aplicação } \\
\text { de boas práticas organizacionais resultando em } \\
\text { um mau desempenho da organização. }\end{array}$ \\
\hline $\begin{array}{l}\text { Análise e melhoria do } \\
\text { processo de avaliação dos } \\
\text { impactos econômicos, } \\
\text { sociais e ambientais de } \\
\text { tecnologias da Embrapa } \\
\text { Pecuária Sudeste. } \\
\end{array}$ & $\begin{array}{l}\text { Bernardi et al. } \\
(2010)\end{array}$ & $\begin{array}{l}\text { Utilização da análise de processos em empresa de } \\
\text { tecnologia da área agropecuária aliada a metodologia } \\
\text { PDCA. O mapeamento ocorre no planejamento (plan) e } \\
\text { a otimização contínua do processo pode ser observada } \\
\text { na etapa de ação (act). }\end{array}$ & $\begin{array}{l}\text { O mapeamento de processos é uma ferramenta } \\
\text { útil na ampliação de melhorias da organização. } \\
\text { O autor propõe que a ferramenta PDCA, através } \\
\text { da modelagem de processos de negócio, deve } \\
\text { ser assimilada e praticada. }\end{array}$ \\
\hline $\begin{array}{l}\text { Modelagem dos processos } \\
\text { de negócio e especificação } \\
\text { de um sistema de controle } \\
\text { da produção na indústria } \\
\text { de autoadesivos. }\end{array}$ & $\begin{array}{l}\text { Georges } \\
(2010)\end{array}$ & $\begin{array}{l}\text { Desenvolvimento de sistema de informação em } \\
\text { empresa de grande porte da indústria de autoadesivos } \\
\text { utilizando a modelagem de processo de negócio. Utiliza } \\
\text { modelagem dos processos com abstração dos dados, } \\
\text { funções e unidades organizacionais pela observação } \\
\text { direta, gerando material para a etapa seguinte, onde foi } \\
\text { elaborado projeto do sistema de informação, finalizando } \\
\text { com o desenvolvimento do sistema. }\end{array}$ & $\begin{array}{l}\text { Conclui ressaltando a validade do instrumento } \\
\text { BPM na ampliação da visão do negócio e na } \\
\text { utilização do conhecimento adquirido como fonte } \\
\text { de melhorias. }\end{array}$ \\
\hline $\begin{array}{l}\text { The critical success factors } \\
\text { of business process } \\
\text { management. }\end{array}$ & Trkman (2010). & $\begin{array}{l}\text { Aplicação de três teorias ((i) contingência. (ii) } \\
\text { capacidades dinâmicas e (iii) tarefa tecnológica), para } \\
\text { demonstrar a necessidade de ajustes entre as tarefas } \\
\text { de processos de negócios e sistemas de informação } \\
\text { em um estudo de caso do setor bancário. }\end{array}$ & $\begin{array}{l}\text { A empresa deve aceitar a mudança em seus } \\
\text { processos para melhorar sua vantagem } \\
\text { competitiva. O alinhamento dos seus processos } \\
\text { de negócio suportado com a correta aplicação do } \\
\text { sistema de informação pode assegurar a } \\
\text { flexibilidade e adaptação contínua de seus } \\
\text { processos essenciais de negócio. }\end{array}$ \\
\hline $\begin{array}{l}\text { Increasing the efficiency of } \\
\text { business processes using } \\
\text { a theory of constraints. }\end{array}$ & $\begin{array}{l}\text { Rhee, Cho e } \\
\text { Bae (2008). }\end{array}$ & $\begin{array}{l}\text { Desenvolvimento de um método baseado na Teoria das } \\
\text { Restrições (TOC) para maximizar a eficiência dos } \\
\text { processos de negócio. O gerenciamento de um } \\
\text { processo pode ser concluído em maneiras diferentes } \\
\text { de acordo com os quais as tarefas em um processo são }\end{array}$ & $\begin{array}{l}\text { Os autores concluem que a aplicabilidade do } \\
\text { modelo oferece melhor desempenho na taxa de } \\
\text { transferência, tempo de ciclo e trabalho em } \\
\text { processos nos mesmos ambientes de trabalho. }\end{array}$ \\
\hline
\end{tabular}




\begin{tabular}{|l|l|l|l|}
\hline & & $\begin{array}{l}\text { atribuídas e quando tais tarefas são executadas. O } \\
\text { modelo foi testado por meio de experimentos de } \\
\text { simulação para validar a eficácia dos seus processos } \\
\text { de negócio. }\end{array}$ & \\
\hline $\begin{array}{l}\text { Análise de componentes } \\
\text { da tecnologia de business } \\
\text { process management } \\
\text { system (bpms) sob a } \\
\text { perspectiva de um caso } \\
\text { prático. }\end{array}$ & $\begin{array}{l}\text { Sordi e Spelta } \\
(2007)\end{array}$ & $\begin{array}{l}\text { Implementação da solução BPMS em uma empresa de } \\
\text { seguros. O processo “Tratar ocorrência de sinistro com } \\
\text { resseguro" é descrito, otimizado e automatizado } \\
\text { utilizando tecnologia BPMS. }\end{array}$ & $\begin{array}{l}\text { Ressalta redução de prazos do processo, } \\
\text { diminuindo documentação e atividades } \\
\text { burocráticas, além de ganhos financeiros devido } \\
\text { à redução de multas. }\end{array}$ \\
& & & \\
\hline
\end{tabular}

\section{METODOLOGIA}

A opção metodológica recai sobre a utilização da observação participante. Além disso, a pesquisa possui caráter descritivo e eventualmente, explicativo (ainda que não seja esse o foco primário).

\section{Tipificação da Pesquisa}

A observação participante consiste, segundo Marconi e Lakatos (2009b), na participação real do pesquisador com a comunidade ou grupo, incorporando e confundindo-se com o grupo. $\mathrm{O}$ pesquisador fica tão próximo quanto um membro do próprio grupo que esta estudando e participa das atividades normais deste. Pode haver grande dificuldade de manter a objetividade, pois o observador participante pode influenciar e ser influenciado pelo grupo, através de simpatias e antipatias pessoais ou pelo choque de referências entre observador e observado. No caso desta pesquisa, em que pesquisadora e gestora da empresa se confundem, é importante a busca da objetividade. Ainda de acordo com os autores, existem duas formas de observação participante, natural e artificial. No tipo de investigação natural o observador pertence à mesma comunidade ou grupo que investiga. Já na artificial o observador integra-se ao grupo com a finalidade de obter informações. Esta pesquisa pode ser verificada, portanto, como uma observação participante natural, implicando a interação entre investigador e os grupos pesquisados, diretamente no contexto da situação. Vale ressaltar que neste tipo de pesquisa o investigador necessita de algumas habilidades, como ser um bom ouvinte, formular boas perguntas, ter flexibilidade para se adaptar a situações inesperadas, ter familiaridade com as questões investigadas e não ter pressa de identificar padrões ou atribuir significados aos padrões observados, conforme explicitado por Marconi e Lakatos (2009a). Assim, utiliza-se de forma enfática neste tipo de pesquisa a habilidade, profissionalismo, flexibilidade e os aspectos emocionais e ideológicos do próprio pesquisador.

Marconi e Lakatos (2009a) afirmam que os conceitos são construções lógicas criadas a partir de interpretações sensoriais e percepções, ou mesmo de experiências bem complexas, não existindo como fenômenos. Desta forma estas construções não existem sem um quadro de referencia estabelecido. Salientam ainda que deva ser possível derivar das assunções da teoria proposições que poderiam ser comparadas às proposições observacionais, de modo a decidir a conformidade da teoria com o fato. Cassiani et al. (1996) afirmam que os conceitos usados na construção de teorias são conceitos abstratos (conceitos que independem de tempo e espaço) 
sendo que a abrangência de uma teoria é determinada pela abstração de seus conceitos ou pela capacidade de o investigador abstrair relações. Neste contexto, esta pesquisa apresenta caráter interpretativo, tendo como última análise a própria organização.

Por fim a pesquisa descritiva refere-se, primordialmente, a descrição de características de determinada população ou fenômenos, ou estabelecimento de relações entre variáveis. Este tipo de pesquisa pode ir além desta identificação de relações entre variáveis, pretendendo determinar a natureza destas relações, tendo, assim, uma aproximação da pesquisa explicativa (GIL, 2009). No caso desta pesquisa, pretende-se entender a natureza e verificar as relações entre a aplicação da metodologia de BPM e a melhora na gestão da organização, caracterizando a pesquisa descritiva.

\section{Coleta de Dados}

O método de coleta de dados refere-se ao meio pelo qual a informação sobre as variáveis é coletada. Os dados serão colhidos pela pesquisadora através de observação e exame de documentos. Para isto é necessário definir as variáveis de interesse a fim de se buscar maior objetividade da pesquisa. Para Gil (2009) as fontes escritas na maioria das vezes são muito ricas e ajudam o pesquisador a não perder tanto tempo na hora da busca de material em campo, sabendo que em algumas circunstâncias só é possível à investigação social através de documentos. Dentre os documentos planeja-se o exame de processos previamente descritos, plano de negócios, análises de mercado, entre outros. Os dados serão o mapeamento de processo, as ações empreendidas pela empresa e o resultado decorrente das ações, além daqueles decorrentes da observação participante e documentos já citados.

\section{Análise de Dados}

A análise dos dados foi realizada no intuito de sintetizar o que foi coletado e expressar as informações de forma a se fazer ser entendido, representando a fase de reflexão crítica do trabalho investigativo e constituindo-se num caminho árduo e de grande responsabilidade. Isto decorre do fato de que por meio dela que se pode transformar tudo aquilo que nos foi confiado, através dos dados empíricos, em interpretações que se sustentem teoricamente. (TEIXEIRA et al., 2008). Ainda segundo os autores, a finalidade da análise de dados é organizar, fornecer estruturas e extrair significados dos dados da pesquisa. Desta forma os autores apontam que as três principais finalidades da análise são a busca do significado dos fenômenos a partir dos dados concretos, confirmar ou contestar hipóteses e ampliar a compreensão da realidade com uma totalidade. Assim, partindo-se das experiências e estudos realizados acerca do tema proposto pela pesquisadora e de todos os dados colhidos, realizou-se a análise dos dados contribuindo com uma reflexão acerca do Gerenciamento de Processos de Negócio e sua aplicação pratica em uma microempresa. A análise identificou as ações estratégicas e operacionais praticadas pela empresa durante o período de coleta de dados e testou quais delas decorreram do uso do BPM 
demonstrando a sua interferência no processo e, por outro lado, explicitando indicações do BPM que não foram consideradas (e/ou utilizadas) na definição e implementação das ações da empresa.

\section{RESULTADOS}

A partir dos métodos já descritos neste trabalho, a aplicação da metodologia BPM na empresa estudada se iniciou pela coleta de dados a fim de se conhecer os processos internos e de se determinar seu impacto na eficiência da gestão organizacional. Para o desenvolvimento desta atividade, optou-se pela análise top-down, isto é, partindo do macroprocesso para processos mais específicos e detalhados. O macroprocesso da empresa pode ser observado na Figura 2, em que o ciclo da atividade fim é representado através de três macro atividades interdependentes e que efetivamente garantem o seu funcionamento.

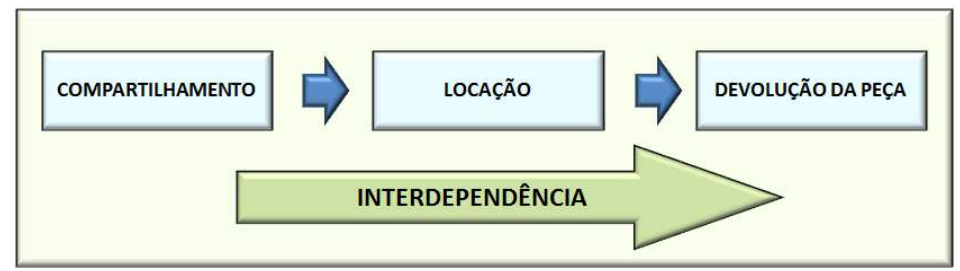

Figura 2: Detalhamento do macroprocesso.

A partir disso, propõe-se o levantamento dos processos mais importantes para o negócio, que podem afetá-lo e carecem de otimização para um melhor desempenho. Esta atividade, denominada mapeamento AS IS, consiste no levantamento e na documentação da situação atual dos processos. Desta forma, garante-se ao analista maiores informações sobre o negócio e grande oportunidade de se identificar fragilidades e possíveis melhorias.

Após a análise pretende-se criar a proposição de um futuro processo, que deverá promover mudança no sentido de sanar as fragilidades e aplicar as melhorias à atual forma de atuação da empresa. Denominado de mapeamento TO BE, esta parte do trabalho consiste na discussão das melhorias, com definição e documentação da situação futura do processo, através do redesenho do processo AS IS. A implementação das mudanças sugeridas será intimamente acompanhada, devendo-se realizar esta tarefa através de indicadores de desempenho que poderão mensurar o resultado. Este trabalho propõe a execução de apenas um ciclo de melhoria, devendo ficar claro que, conforme a literatura já apresentada, esta é uma atividade contínua e que deve acompanhar a gestão da organização, tendo em vista que, à medida que ocorrem alterações no ambiente ou que a empresa cresce, dentre outros fatores, novas oportunidade de melhoria podem ser encontradas.

Primeiramente, percebe-se que o macroprocesso demonstrado na Figura 2 é um conjunto de processos interdependentes sendo todos eles necessários para o funcionamento da empresa. Dentre os três processos representados (Compartilhamento, Locação e Devolução da peça) pode- 
se dizer que o processo Compartilhamento possui alto impacto. Ele trata da forma como as clientes disponibilizam suas peças para a loja. Sendo a primeira loja no Brasil a realizar este serviço, é muito importante que este processo seja otimizado e documentado, no sentido de deixá-lo o mais claro possível e provendo o melhor resultado. Este é o processo responsável pelo grande diferencial da empresa, que a torna diferente de outras empresas de locação. Isto se deve porque, conforme já explicitado, o mercado conta com diversas lojas de locação de vestido para eventos especiais, entretanto, as lojas geralmente compram os vestidos para em seguida locá-los. Estas peças sofrem depreciação a cada uso e é necessário que a peça renda um número de aluguéis suficiente para pagar o investimento e ter uma boa margem de lucro. No caso da empresa estudada, apenas se investe na peça que for realmente locada, proporcionalmente ao número de locações, já que este investimento é revertido para o pagamento de comissões para as clientes que concederam suas peças para a loja. Além disso, ainda pensando na depreciação das peças pelo uso, caso os vestidos fossem comprados de fornecedores pela empresa, após uma quantidade específica de locações, poderiam ficar inutilizáveis, gerando perdas importantes. No modelo de negócio da empresa analisada as peças são devolvidas a partir do momento que passam a não ser mais utilizadas, seja por falta de locação ou por depreciação da peça, não havendo este risco. Todas estas questões demonstram o potencial que o processo Compartilhamento tem para influenciar o desempenho da empresa, justificando sua escolha para ser otimizado.

O processo Locação também deve ser avaliado tendo em vista que é o responsável pela captação de receita e, por isso, de grande importância para a saúde financeira e pelo funcionamento geral da empresa. O processo Compartilhamento não poderia funcionar sem o processo Locação das peças, resultado final e objetivo do compartilhamento. Sendo assim, estes foram os dois processos mais relevantes e escolhidos para serem trabalhados.

O mapeamento do processo AS IS se deu através da participação da pesquisadora no diaa-dia da empresa, pela conversa com demais funcionários e pela análise de documentos. Assim foi possível levantar informações suficientes para o mapeamento tanto do processo Compartilhamento quanto do processo Locação de peças. A Figura 3 apresenta o processo de compartilhamento AS IS.

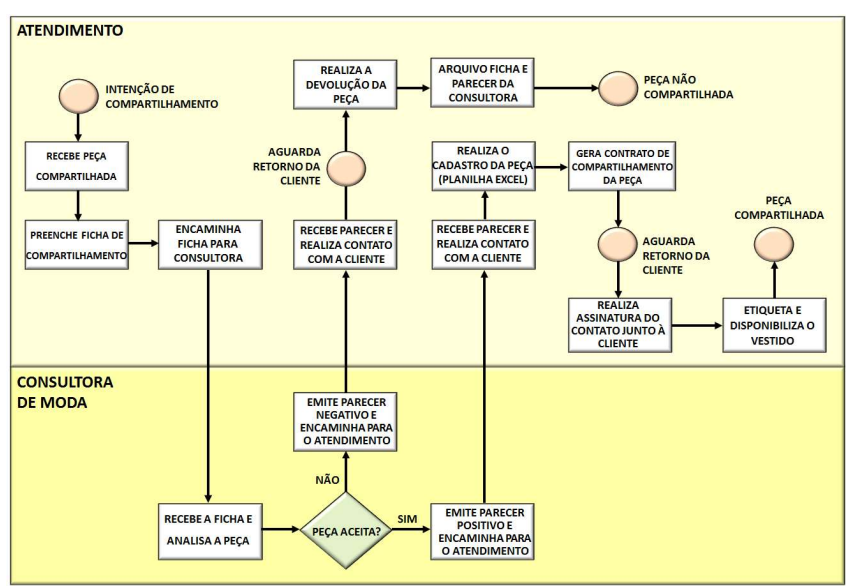

Figura 3: Processo compartilhamento AS IS. 
O goal do processo, isto é, seu objetivo ou motivo de ser executado é receber as peças das clientes e, de acordo com o caso, realizar os procedimentos necessários para que a peça seja colocada à disposição das clientes na loja. Ele se inicia, portanto, com a intenção de compartilhamento por parte de alguma cliente. O setor responsável (Atendimento) recebe a peça e preenche a Ficha de Compartilhamento, documento preenchido manualmente, e o envia para setor Consultora de Moda. Após análise, a consultora define se a peça foi aceita, seguindo requisitos previamente definidos como estado de depreciação da peça, tipo de tecido, quantidade de peças semelhantes já disponíveis, dentre outros. Caso a peça não seja aceita, emite-se um parecer negativo que é anexado à Ficha de Compartilhamento, sendo estes encaminhados de volta para o Atendimento. Assim, a cliente é contatada e deve retornar a loja para buscar a peça, sendo os documentos arquivados pelo responsável pelo Atendimento. No caso de peças aceitas a consultora emite parecer positivo e, anexado à Ficha, encaminha-o para o Atendimento. Neste caso, o atendimento recebe a peça e registra os dados em arquivo (Excel), utilizado pra manter o controle das peças. Em seguida, gera manualmente um contrato de administração de bens que ficará armazenado até que a cliente retorne à loja. Neste momento o contrato é assinado e arquivado. Por fim, pode se realizar procedimentos para a efetiva disponibilização do vestido, já devidamente etiquetado.

Com este processo foi possível observar diversas lacunas que poderiam ser trabalhadas: Excesso de burocracia: documentação em papel causando gasto excessivo de folhas e maior tempo do processo; Repetição de atividades: os dados das peças são passados primeiro para a Ficha de Compartilhamento e depois para o arquivo de controle (Excel), devendo ser trabalhados em dois momentos diferentes; Atividades manuais: o contrato é gerado manualmente, gastandose mais tempo na tarefa e aumentando-se o risco de erros; Atividades que não agregam valor: a Ficha de Compartilhamento passa a não ser mais utilizada após as informações serem passadas para o arquivo de controle, gerando atividades que demandam esforço, mas não agregam valor ao processo; Controle em sistema não oficial: o acompanhamento de peças deveria ser realizado em software oficial, projetado especificamente para controlar as necessidades do negócio de acordo com as tecnologias disponíveis. Entretanto, este controle é realizado via Excel, software genérico e que não atende a necessidades específicas; Riscos desnecessários: a Ficha de Compartilhamento deve ser enviada para a consultoria, entretanto, sendo uma ficha de papel, que é levada entre os setores do negócio, há risco de perda ou dano, possibilitando o risco de se perder informações importantes. Precisamente, foi levantado um caso em que se perdeu a ficha e por este motivo o registro da peça foi apagado. Não se sabia quem era a dona da peça e a mesma ficou guardada até manifestação da cliente, algo que pode influenciar bastante na segurança e na imagem da organização. Situação que também apresenta risco desnecessário para o negócio está no fato de o processo prever que o setor Atendimento contate a cliente para informá-la do parecer da peça, o que geralmente ocorre por telefone. Sem registro da atividade 
(como por exemplo, o registro de um e-mail enviado), há o risco da cliente se descontentar por não ter tido retorno e não termos registros de como o contato foi realizado.

Em seguida pode se passar para a análise do processo de locação, conforme demonstrado na Figura 4.

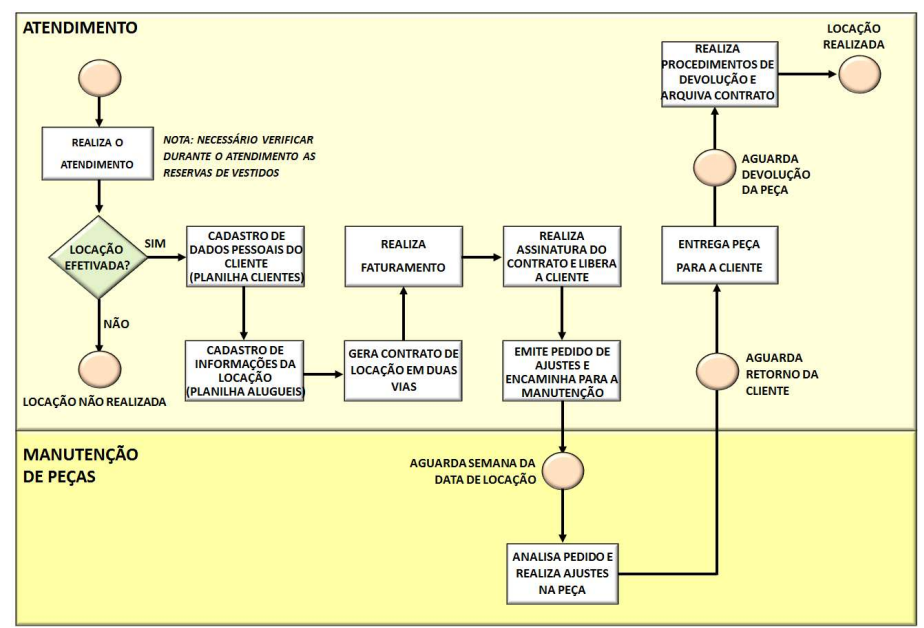

Figura 4: Processo locação de peças AS IS.

O processo de locação tem por objetivo fechar contratos de locação das peças compartilhadas e realizar a prestação do serviço proposto, garantindo a fonte de receita da empresa. Ele se inicia com a intenção de locação por parte da cliente e a realização pelo setor de atendimento. Esta parte do processo não foi detalhada tendo em vista que não possui padrões específicos e deve ser realizado de acordo com o perfil da cliente. É preciso ressaltar, entretanto, que neste momento é necessário acompanhar a planilha de locações, de acordo com as peças que a cliente demonstra interesse. Esta planilha contém as informações acerca das peças que estão reservadas para datas futuras e sua manutenção é muito importante para que uma mesma peça não seja locada para duas clientes diferentes na mesma data. Caso a locação não seja efetivada o processo finaliza. Se a cliente optar por alguma peça o setor de atendimento deve realizar diversos procedimentos, iniciando pelo cadastro dos dados pessoais da cliente na planilha específica. Em seguida as informações da locação são inseridas na planilha de acompanhamento de locações. A responsável pelo setor gera contrato de locação e realiza a impressão em duas vias, ficando uma com a cliente e uma com a empresa. Passa-se então para o faturamento da peça, com recebimento dos valores devidos e assinatura do contrato junto à cliente, que é liberada. Por fim, a responsável emite o pedido de ajustes da peça e o encaminha ao setor de Manutenção de Peças. Próximo à data que o vestido foi reservado este setor realiza os ajustes necessários de acordo com o pedido e o devolve ao setor de atendimento, para deixá-lo aguardando o momento em que a cliente irá buscá-lo. Após o uso a cliente devolve a peça, devendo a responsável pelo atendimento recebê-la, realizar todos os procedimentos de devolução (como envio para lavanderia e reparos) e, por fim, arquivar o contrato. 
Com este processo devidamente mapeado e analisado foi possível observar as lacunas e oportunidades de melhoria conforme detalhamento abaixo: Processo moroso: devido cadastramento de dados ser realizado em diversas planilhas, além da atividade "gerar contrato" ser manual, aumentando o tempo gasto em sua realização; Atividades manuais: o contrato é gerado manualmente, gastando-se mais tempo na tarefa e aumentando-se o risco de erros; Controle em sistema não oficial: o cadastro de clientes, o acompanhamento de locações e a emissão de pedido de ajustes deveriam ser realizados em software oficial, projetado especificamente para controlar as necessidades do negócio de acordo com as tecnologias disponíveis. Entretanto, este controle é realizado via Excel, software genérico e que não atende a necessidades específicas; Riscos desnecessários: como o acompanhamento de locações é realizado via planilha, devido a erros no preenchimento ou morosidade, acontece, em algumas situações, da planilha ser completada apenas ao final do dia. Entretanto, pode ocorrer de uma locação ser realizada para determinado dia e no mesmo dia, antes da planilha ser finalizada, outra cliente solicitar o mesmo vestido para a mesma data. Como o registro não consta na planilha o vestido pode ser locado com duplicidade, o que gera problemas graves para a empresa que fecha contratos com duas clientes, não podendo, portanto, cumpri-los. Este é um erro de alto impacto que prejudica muito a imagem da empresa; Falta de controle do processo: a falta de integração das atividades também gera falta de controle do processo como um todo. Por exemplo, o arquivamento de contratos é apenas uma formalidade, já que os papeis arquivados não são facilmente localizados em caso de necessidade.

Após observação destes processos e seguindo a metodologia proposta pela pesquisa, parte-se para a análise dos possíveis pontos de melhoria. Esta análise busca o ganho de competitividade a partir das raízes dos problemas encontrados durante o mapeamento dos processos. Foram verificadas as disfunções e pontos de melhoria, encontradas ao longo do processo, buscando melhorar a relação entre investimento e retorno e otimizar os recursos disponíveis da organização. Esta tarefa se dá no sentido de atribuir obrigações e responsabilidades aos colaboradores da empresa de forma clara; padronizar os processos a fim de se garantir que o serviço permaneça sempre com nível de qualidade satisfatório; implantar tecnologias adequadas ao negócio, que busquem melhoria continua dos processos internos e que estejam de acordo com os objetivos estratégicos da organização e, por fim, otimizar o tempo, buscando sempre a melhoria dos resultados, tanto financeiros quanto através de indicadores de qualidade e desempenho, propiciando informação para uma melhor gestão e poder de decisão com melhores escolhas para a alocação de recursos, contratação de funcionários, treinamentos específicos para cada setor empresarial e necessidade de reestruturação organizacional; A partir disso, foram propostos os processos TO BE, apresentado nas Figuras 5 e 6 : 


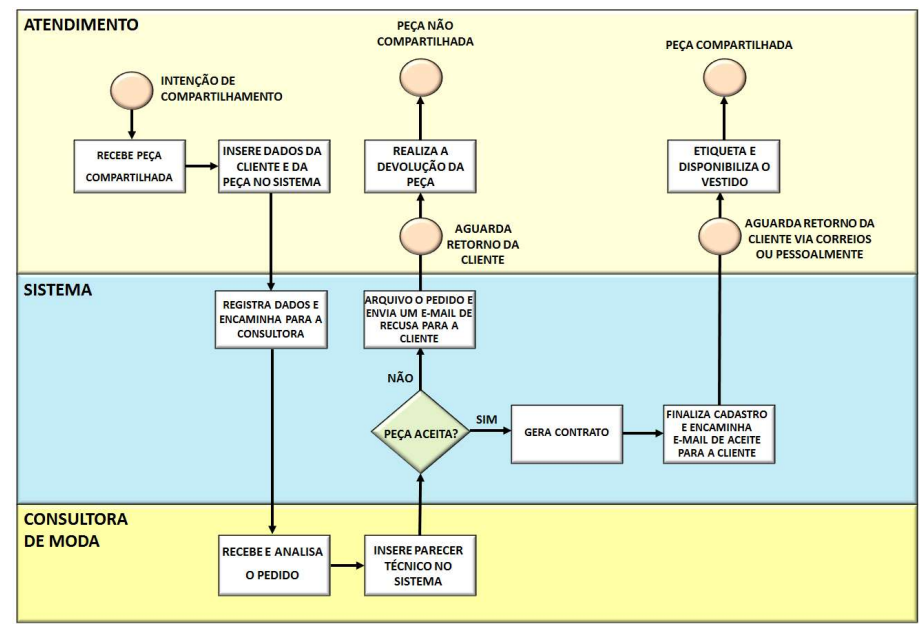

Figura 5: Processo compartilhamento $T O B E$.

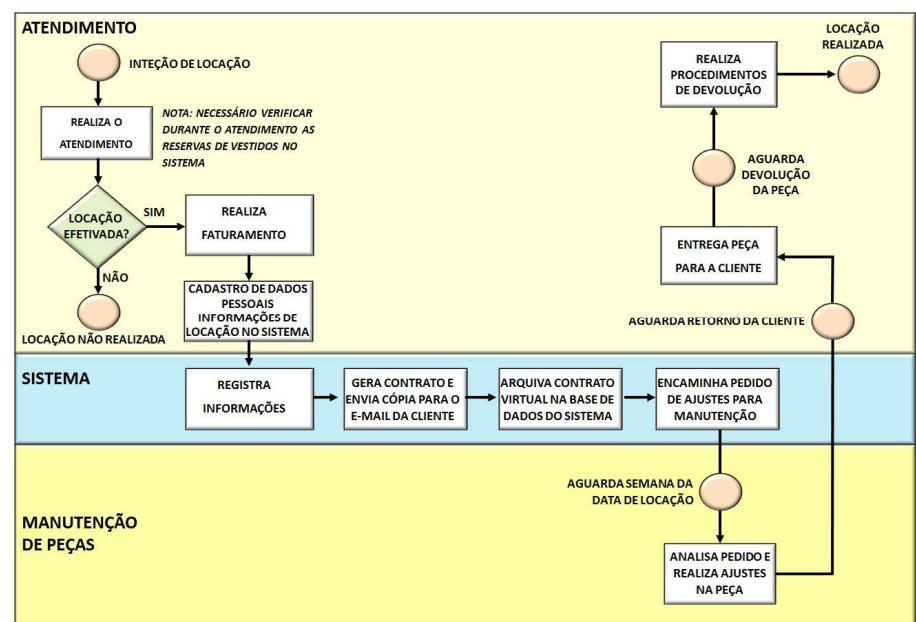

Figura 6: Processo locação de peças TO BE.

As implantações de melhoria propostas para estes processos basearam-se na redução de atividades, principalmente através da criação de um software de gerenciamento formulado especificamente para as necessidades da empresa. Durante um período de dois meses o software foi elaborado juntamente a uma empresa responsável, sendo concebido de acordo com a proposição do processo TO BE. Além disso, foram retiradas atividades excessivamente burocráticas, arquivamentos desnecessários, gastos que poderiam ser substituídos, dentre outros, conforme será relatado adiante.

O processo Compartilhamento TO BE, conforme pode se observar na Figura 4, tornou-se menor e mais intuitivo em suas atividades. Ele se inicia também com a intenção de compartilhamento de peças por parte de alguma cliente. Entretanto, a primeira alteração substancial recai sobre o fato de se ter eliminado a Ficha de Compartilhamento. Assim, os dados são inseridos diretamente no sistema de gestão. Isso significa redução do risco de se perder informações, conforme já explicitado acima, e redução de gastos com papel e impressão. Os dados da cliente e do vestido serão inseridos diretamente no sistema, que o registra e encaminha para a consultora, aumentando a agilidade do processo. Na posse dos dados e do vestido a consultora pode então emitir seu parecer diretamente no sistema, de acordo com os mesmos 
critérios já estabelecidos pela empresa. O próprio sistema realiza a triagem das peças aceitas e encaminha, através de e-mail, o retorno para as clientes. O envio automático de e-mail é uma excelente opção neste nível de negócio, evitando gastos, por exemplo, com telefonemas/ papéis e gerando registro de que a informação foi enviada, o que gera mais segurança para a empresa. No caso de peças que não foram aceitas, o arquivamento é apenas virtual, melhorando o desempenho do processo e evitando atividades burocráticas que não agregam valor. Neste caso o setor de atendimento precisa apenas aguardar o retorno da cliente para buscar a peça a ser devolvida.

Para o caso de peças aceitas, o próprio sistema gera o contrato e o envia automaticamente para o e-mail cadastrado da cliente. Neste caso a própria cliente deverá realizar a impressão do contrato e enviá-lo assinado para a loja. Com isto, diminui o gasto, que era até então feito pela loja, além de realizar uma diferenciação do serviço no sentido de dar maior comodidade para a cliente, que pode enviá-lo pessoalmente ou por correio, não sendo mais necessário que obrigatoriamente compareça a loja. Assim o setor de atendimento aguarda a chegada do contrato assinado e pode, então, proceder com os procedimentos finais para etiquetação e liberação das peças para serem locadas. No quadro 2 observa-se a relação entre o problema exposto e a resolução proposta após o ciclo de melhorias do processo Compartilhamento.

Quadro 2: Relação entre problemas diagnosticados e implementação de melhorias no processo compartilhamento.

\begin{tabular}{|c|c|c|c|c|}
\hline $\begin{array}{l}\text { PROBLEMA DIAGNOSTICADO } \\
\times \\
\text { IMPLANTAÇÃO DE MELHORIAS }\end{array}$ & 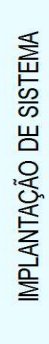 & 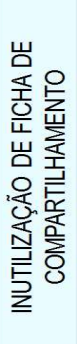 & 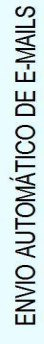 & 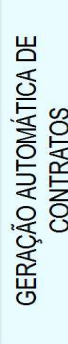 \\
\hline EXCESSO DE BUROCRACIA & $\mathbf{x}$ & $\mathbf{x}$ & $\mathbf{x}$ & \\
\hline REPETIÇÃO DE ATIVIDADES & $\mathbf{x}$ & $\mathbf{x}$ & & \\
\hline ATIVIDADES MANUAIS & $\mathbf{x}$ & & & $\mathbf{x}$ \\
\hline ATIVIDADES QUE NÃO AGREGAM VALOR & $\mathbf{x}$ & $\mathbf{x}$ & & \\
\hline CONTROLE EM SISTEMA NÃO OFICIAL & $\mathbf{x}$ & & & \\
\hline RISCOS DESNECESSÁRIOS & $\mathbf{x}$ & $\mathbf{x}$ & $\mathbf{x}$ & \\
\hline
\end{tabular}

Passando para o processo Locação de Peça TO BE, que inicia com a intenção de locação por parte de alguma cliente, nota-se que este concentrou grande parte das atividades no sistema desenvolvido para gerir o negócio, tornando-o mais simples e fluido para o restante dos setores. 0 atendimento à cliente se manteve, com todos os aspectos necessários à adequação de acordo com o perfil de cada cliente. Vale ressaltar que a verificação de reservas dos vestidos também se manteve, entretanto, passou a ser realizada no sistema e não na planilha de acompanhamento de locações. Assim, caso haja uma locação efetivada a responsável pelo atendimento deverá realizar 
o faturamento da peça e em seguida o cadastramento dos dados pessoais e da locação no sistema.

É importante frisar que essa diminuição de atividades administrativas concentradas neste ponto do processo possui grande potencial de diminuir erros por parte dos funcionários, evitandose gastos, atrasos e outros tipos de complicações decorrentes destes erros. O sistema registra as informações inseridas pela funcionária e gera o contrato de locação, enviando uma cópia automaticamente para o e-mail da cliente. Isto é importante para se evitar o desperdício, já que passamos a imprimir somente a cópia da empresa. O sistema arquiva o contrato virtual e por fim encaminha o pedido de ajustes para a Manutenção de Peças. O responsável do setor aguarda a semana da data de locação e realiza os ajustes da peça. Quando a cliente retorna à loja, a responsável pelo Atendimento entrega a peça para a cliente e, por fim, após a devolução da peça, ela realiza os procedimentos de devolução. O Quadro 3 refere-se à relação entre o problema exposto e a resolução proposta após o ciclo de melhorias do processo Locação de Peças:

Quadro 3: Relação entre problemas diagnosticados e implementação de melhorias no processo locação de peças.

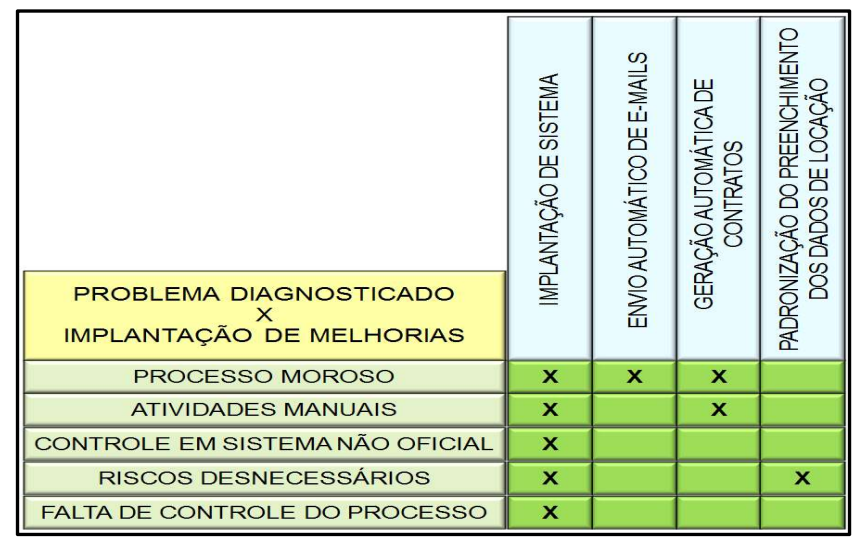

Após o desenvolvimento deste trabalho é importante propor para o negócio os indicadores de desempenho, já que a medição de resultados é etapa importante para o gerenciamento. Estes indicadores devem gerar informação ao analista do processo quanto à alocação de recursos e a possibilidade de atingir metas previamente estabelecidas pela organização, a fim de que futuras decisões sejam tomadas de forma mais correta e assertiva. Estes dados serão críticos para o próximo ciclo de melhorias e por este motivo deve ser feito com qualidade, mensurando o desempenho do processo e revisando sua eficiência/eficácia.

Os Indicadores de Desempenho propostos nesta pesquisa, conforme explicitado na revisão da literatura, obedecem aos requisitos de especificidade, relevância, alcançabilidade, mensurabilidade e serem atrelados a prazo. Seguindo a metodologia de BPM, os indicadores foram construídos considerando o tamanho da empresa, o seu nível de organização e a possibilidade de armazenamento de informações. Sendo assim, os indicadores são monitorados por ferramentas simples de acordo com as métricas estabelecidas. 
Para cada indicador foi proposto: Nome: para facilitar sua identificação; Objetivo: motivo pelo qual o indicador foi criado. Elucidação da informação que deverá fornecer; Periodicidade: métrica a ser utilizada com relação ao prazo de medição do indicador; Fonte: local (setor ou ferramenta) de recolhimento das informações; Processo: referência ao processo que se destina acompanhar. A partir de toda a análise realizada os indicadores de desempenho foram propostos, resultando em cinco indicadores, especificados conforme apresentado no Quadro 4.

Quadro 4: Indicadores de desempenhos dos processos analisados.

\begin{tabular}{|c|c|c|c|c|c|}
\hline & INDICADOR 1 & INDICADOR 2 & INDICADOR 3 & INDICADOR 4 & INDICADOR 5 \\
\hline NOME & $\begin{array}{l}\text { TEMPOMEEDIO DO } \\
\text { PROCESSO }\end{array}$ & $\begin{array}{l}\text { TEMPOMÉDIODO } \\
\text { PROCESSO }\end{array}$ & $\begin{array}{l}\text { CUSTOMEDDIOSETOR } \\
\text { ADMINISTRATIVO }\end{array}$ & $\begin{array}{l}\text { QUANTIFICAÇ̄̃ODE } \\
\text { ERROS }\end{array}$ & $\begin{array}{l}\text { QUANTIFICACCÃODE } \\
\text { ERROS }\end{array}$ \\
\hline OBJETIVO & $\begin{array}{l}\text { ACOMPANHAR O } \\
\text { TEMPOMEEDIOGASTO } \\
\text { PELAS ETAPAS DO } \\
\text { PROCESSO, } \\
\text { DESCONSIDERANDO } \\
\text { A ESPERAPELO } \\
\text { RETORNODA } \\
\text { CLIENTE }\end{array}$ & $\begin{array}{c}\text { ACOMPANHAR O } \\
\text { TEMPOM MEDIO GASTO } \\
\text { PELASETAPAS DO } \\
\text { PROCESO, } \\
\text { DESCONSIDERANDO } \\
\text { AESPERA PELO } \\
\text { RETORNODA } \\
\text { CLIENTE }\end{array}$ & 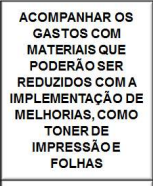 & 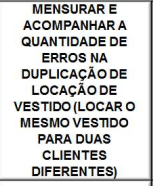 & $\begin{array}{l}\text { MENSURAR E } \\
\text { ACOMPANARAR } \\
\text { QUANTDADE DE } \\
\text { ERROS AO GERAR } \\
\text { CONTRATOS }\end{array}$ \\
\hline PERIODICIDADE & A CADA ATIVIDADE & A CADA ATIVIDADE & MENSAL & BIMESTRAL & BIMESTRAL \\
\hline FONTE & DADOS DO SISTEMA & DADOS DO SISTEMA & SETOR FINANCEIRO & SETORATENDIMENTO & $\begin{array}{l}\text { SISTEMAE SETOR } \\
\text { ATENDIMENTO }\end{array}$ \\
\hline PROCESSO & COMPARTILHAMENTO & LOCAÇ̄̃O DE PEÇAS & \begin{tabular}{|c|} 
LOCAÇÃODE PEÇAS \\
$E$ \\
COMPARTILHAMENTO
\end{tabular} & LOCAÇ̄̃̄ODE PEÇAS & $\begin{array}{l}\text { LOCAÇÃODE PEÇAS } \\
E \\
\text { COMPARTLLHAMENTO }\end{array}$ \\
\hline
\end{tabular}

A modelagem de processos de negócio propicia ao gestor grande conhecimento do negócio, conforme pôde ser observado durante a execução deste ciclo de melhorias. Pelos indicadores foi possível notar as mudanças do processo, etapa inicial que antecederia um novo ciclo de melhorias, não sendo executado considerando que este objeto de estudo prevê a execução de apenas um ciclo de melhoria. Essas melhorias foram identificadas em pequeno grau, devendo se considerar que o monitoramento ocorreu durante o prazo de dois meses, devido cronograma da pesquisa. Pela análise destas melhorias previamente identificadas percebe-se a tendência da melhoria do processo, com grande possibilidade de identificação de diversas outras melhorias com maiores prazos de acompanhamento. Vale ressaltar também melhorias relacionadas à documentação da informação, possibilitando que esta possa ser transmitida a outros funcionários de forma mais assertiva e clara.

Sem dúvida, quanto maior a empresa maior potencial para melhorias haverá no mapeamento e análise de processos de negócio. Com as mudanças descritas pôde se perceber pequenos ganhos na redução de custos, por exemplo, de papel e impressão, menor riscos de erros, o que em longo prazo significa benefícios para a imagem da organização, dentre outros. Entretanto a otimização em um processo estratégico de uma organização de alto nível certamente poderia gerar redução de custos consideráveis ou melhora do desempenho que significasse efetivamente mais clientes ou receitas maiores.

Conforme já relatado na literatura esses ganhos podem promover ao negócio diferencial competitivo importante para a manutenção da organização no mercado. Analisando a questão proposta por esta pesquisa, aonde deveria analisar a aplicabilidade da ferramenta de BPM em empresa de serviços de locação de vestidos é possível concluir que, mesmo que isto ocorra em graus diferentes e dependa da maturidade da organização e do nível técnico do analista, diversos 
ganhos podem ser conquistados com o mapeamento dos processos de negócio, inclusive em empresas pequenas, com processos recentemente implantados ou iniciando suas atividades.

À medida que se desenvolvem os ciclos de melhoria, é possível aumentar o nível de detalhamento das tarefas, tornando-as mais confiáveis e mais fáceis de serem repassadas aos funcionários. Além disso, o mapeamento e análise de processos é um constante aprendizado. Quanto mais se pratica, melhor será a visão do analista, ficando mais apto a detectar possibilidades de melhoria e lacunas do processo atual. Espera-se que a cada ciclo de melhoria novas oportunidades sejam localizadas, sendo preferível que uma mesma pessoa seja responsável por acompanhar a tarefa, tendo cada vez mais conhecimento do processo e propondo cada vez melhores soluções.

Quanto aos indicadores de desempenho, quanto mais complexa a organização, mais complexos serão seus processos e, consequentemente, a medição de seu desempenho. No caso estudado a medição se deu através do sistema implantado, podendo também ser suportado por planilhas ou quadros de medição. Não convém para uma pequena empresa a utilização de medidores de alto desempenho e tecnologia, que estariam em desacordo com a tecnologia utilizada pelo próprio negócio. Entretanto, à medida que a empresa cresce e que o ciclo de melhoria se torna mais complexo, como ocorre nas grandes empresas, é possível utilizar medidores de alta tecnologia como ferramentas de Business Inteligence (BI) ou outras tecnologias que não serão detalhados nesta pesquisa.

\section{CONCLUSÕES}

Recuperando todo o trabalho desenvolvido nesta pesquisa, observa-se que foi realizado um ciclo de melhoria de processos de negócio a partir da ferramenta de BPM em empresa de pequeno porte de serviços do ramo da moda. Para isso o macroprocesso que caracteriza a empresa foi detalhado, levantando-se os processos mais relevantes do negócio, neste caso o Compartilhamento e a Locação de peças. Esses processos foram mapeados em sua situação atual (modelo AS IS). Em seguida foi realizada a análise do processo com identificação de lacunas e possibilidades de melhoria, resultando no remapeamento do processo (modelo TO BE). As alterações propostas foram implantadas através de software de gerenciamento do negócio e da padronização de novos procedimentos internos, quanto à documentação, arquivamento de contratos, utilização de fichas de preenchimento manual, dentre outras. Finalmente, indicadores de desempenho foram propostos para que fosse realizada a manutenção das mudanças e acompanhados pelos gestores do negócio, afirmando a possibilidade de melhorias do negócio.

Conclui-se, portanto, a partir da questão de pesquisa "Qual a aplicabilidade da metodologia de Gerenciamento de Processos de Negócio (BPM) em uma organização de serviços no setor de moda?", que é possível aplicar a metodologia para este tipo de empresa, o que pode ser extravasado para outros tipos de organização, desde que observados os requisitos para sua utilização e que os mesmos sejam devidamente adequados. Quanto aos objetivos específicos 
propostos por esta pesquisa (obter um entendimento prático da ferramenta, testar se a aplicação da ferramenta gera benefícios na gestão da empresa, avaliar os resultados advindos da aplicação e aplicar as descobertas propiciadas pela pesquisa), infere-se que foi possível obter conhecimento prático da ferramenta, o que pode ajudar futuros pesquisadores a entender, mesmo que exemplificado por um processo de menor maturidade, a forma como as melhorias da ferramenta BPM são alcançadas. Além disso, o teste da aplicação da ferramenta foi satisfatório, gerando benefícios para a empresa pesquisada. A avaliação de resultados advindos da aplicação serviu de exemplo para demonstrar este resultado satisfatório. Por fim, a aplicação das descobertas propiciadas pela pesquisa foi de grande valia para a empresa. A implantação do software, moldado a partir do processo proposto para o negócio, pôde transcorrer de forma mais assertiva, diminuindo a chance de erros e melhorando o desempenho desta etapa do negócio. A automação de processos é uma etapa crítica no crescimento de uma empresa e por isso a utilização da metodologia BPM foi de grande valia para a empresa.

Espera-se que a empresa mantenha os ciclos de melhoria, no sentido de fornecer uma ferramenta capaz de estimular continuamente o desenvolvimento de seus processos internos e, consequentemente, melhorar seu desempenho. Como contribuição, este trabalho propiciou a verificação e análise da forma como se da aplicação da metodologia de BPM em uma empresa de serviços de pequeno porte, diferente dos trabalhos encontrados na literatura, em que se demonstra sua utilização em processos mais maduros e empresas maiores. Isto abre caminho para novas pesquisas na área e sugestiona para a utilização da ferramenta como forma de melhorar o desempenho e a gestão de negócios em empresas semelhantes, a partir do estudo e adequação da ferramenta.

Dentre os limitadores que podem interferir na pesquisa, ressalta-se o fato do monitoramento ter sido realizado por prazo curto, impedindo a identificação mais assertiva de tendências quanto à observação ou não das melhorias dos processos. Quanto maior o prazo de monitoramento melhor a qualidade das informações obtidas, bem como a preparação para o ciclo de melhorias seguinte. Destaca-se que quanto mais prática e treinamento, mais apto o analista de processos se torna na identificação e proposição de propostas de melhoria.

Sendo assim, é possível que diferentes pesquisadores obtivessem melhorias em maior e menor grau de acordo com o nível crítico da análise realizada. Por fim, deve-se perceber que, quanto ao fato de pesquisadora e gestora da organização se confundir, pode haver um dualismo no que se refere à influência na pesquisa. Por um lado, este fato aumenta o acesso a informações e o conhecimento acerca da empresa, o que geram dados mais relevantes e confiáveis. Por outro, pode ocorrer à interpretação de dados de forma tendenciosa, seguindo conjecturas advindas do conhecimento profundo e anterior da organização. Tentou-se impedir que isto viesse a ocorrer seguindo-se o mais rigorosamente possível as etapas da ferramenta de BPM. Assim, a revisão teórica realizada nesta pesquisa foi de grande valia no sentido de demonstrar a forma como a ferramenta é utilizada em empresas maiores e servir de embasamento para a forma como ela 
seria aplicada na empresa estudada. Por fim, é necessário pontuar a necessidade de maiores estudos que padronizem e adéquem a utilização da ferramenta BPM em cenários diversos, incluindo empresas de serviços e de pequeno porte, uma vez que foram demonstrados os benefícios que esta prática gera para uma organização.

\section{REFERÊNCIAS}

ABPMP. Association of Business Process Management Professionals. Guia para o Gerenciamento de Processos de Negócio: Corpo Comum de Conhecimento (BPM CBOK). Versão 2, Terceira liberação em português, 2009.

BERNARDI, A. C. C.. et al. Análise e melhoria do processo de avaliação dos impactos econômicos, sociais e ambientais de tecnologias da Embrapa Pecuária Sudeste. Gestão \& Produção, São Carlos, v.17, n.2, p. 297-316, 2010.

BOER, F. G.; MÜLLER, C. J.; CATEN, C. S. t.. Assessment model for organizational business process maturity with a focus on BPM governance practices. Business Process Management Journal, v.21, n.4, p. 908-927, 2015

BROCKE, J. V.; SCHMIEDEL, T.; RECKER, J.; TRKMAN, P.; MERTENS, W.; VIAENE, S.. Ten principles of good business process management. Business Process Management Journal, v.20, n.4, p.530-548, 2014.

CASSIANI, S. B.; CALIRI, M. H. L.; PELÁ, N.T. R.. A teoria fundamentada nos dados como abordagem da pesquisa interpretativa. Revista latino-americana de enfermagem, v.4, n.3, p.75-88, 1996.

CARRARA, A. R.. Implantação de sistema BPMS para a gestão por processos: uma análise crítica. Dissertação (Mestrado em Engenharia) - Escola Politécnica da Universidade de São Paulo, São Paulo. 2011.

CRUZ, T.. Sistemas, Métodos \& Processos. 2 ed. São Paulo: Atlas, 2010.

DAVENPORT, T.. Reengenharia de processos. 2 ed. Rio de Janeiro: Campus, 1994.

GEORGES, M. R. R.. Modelagem dos processos de negócio e especificação de um sistema de controle da produção na indústria de auto-adesivos. JISTEM Journal of Information System Technology Management, v.7, n.3, p.639-668, 2010.

GIL, A. C.. Como elaborar Projetos de Pesquisa. 4 ed. São Paulo: Atlas , 2009.

GONÇALVES, J. E. L.. As empresas são grandes coleções de processos. RAE - Revista de Administração de Empresas, v.40, n.1, p.6-19, 2000.

HAMMER, M.. A empresa voltada para processos. HSM Management, v.2, n.9, 1998.

JOHANSSON, H.; MCHUGH, P.; PENDLEBURY, J.; WHEELER III, W.. Processos de negócios: como criar sinergia entre a estratégia de mercado e a excelência operacional. In: CONGRESSO BRASILEIRO DE ENSINO DE ENGENHARIA. Anais. São Paulo: Pioneira, 2004

MARCONI, M. A.; LAKATOS, E. M.. Metodologia Científica. 5 ed. São Paulo: Atlas, 2009a.

MARCONI, M. A.; LAKATOS, E. M.. Técnicas de Pesquisa. 7 ed. São Paulo: Atlas, 2009b.

MAXIMIANO, A. C. A.. Teoria Geral da Administração: da revolução urbana à revolução digital. 6 ed. São Paulo: Atlas, 2005.

MILAN, G. S.; VERSETTI, R.. Melhorias em processos com impacto na eficiência operacional: um estudo ambientado em um laboratório de análises clínicas. Rio Grande do Sul: ABREPO, 2012. 
MUCKENBERGER, E.; et al. Gestão de processos aplicada à realização de convênios internacionais bilaterais em uma instituição de ensino superior pública brasileira. Produção, v.23, n.3, p.637-651, 2013.

NETTO, F. S.. Gerenciamento de Processos de Negócio: um estudo teórico comparativo sob as óticas da Gestão Empresarial e da Tecnologia da Informação. São Paulo: FEA/USP, 2008.

NOGUEIRA, C. A.. Proposta de instrumento para medição do estado atual da gestão por processos nas organizações brasileiras. São Paulo: Universidade de São Paulo, 2012.

PAIM, R.. Engenharia de processos - conceitos e prática. Monografia (Engenharia da Produção) Escola de Engenharia/UFRJ, Rio de Janeiro, 2001

PIDD, M.. Modelagem empresarial: ferramentas para tomada de decisões. Porto Alegre: Bookman, 1999.

PORCIDES, L. M.. Gestão por processos. São Paulo: FAE Training, 2012.

PRADELLA, S.. Gestão de Processos: uma Metodologia Redesenhada para a Busca de Maior Eficiência e Eficácia Organizacional. Revista Gestão \& Tecnologia, v.13, n.2, p.94-121, 2013.

RAMESH, B.; JAIN, R.; NISSEN, M.; XU, P.. Managing context in business process management systems. London: Published online: 2005.

RHEE, S. H..; CHO, N. W.; BAE, H.. Increasing the efficiency of business processes using a theory of constraints. London: Published online, 2008.

SKRINJAR, R.; TRKMAN, P.. Increasing process orientation with business process management: Critical practices'. International Journal of Information Management. v.33, p.48-60, 2013.

SORDI, J. O.; SPELTA, A. G.. Análise de componentes da tecnologia de Business Process Management System (BPMS) sob a perspectiva de um caso prático. JISTEM: Journal of Information Systems and Technology Management, v.4, n.1, p.71-94, 2007.

TEIXEIRA, M. A.; NITSCHKE, R. G.; PAIVA, M. S.. Análise dos dados em pesquisa qualitativa: um olhar para a proposta de Morse e Field. Revista da Rede de Enfermagem do Nordeste, v.9, n.3, p.125-134, 2008.

TRKMAN, P.. The critical success factors of business process management. International Journal of Information Management. v.30, p.125-134, 2010.

WANG, M.; WANG, H.. From process logic to business logic-A cognitive approach to business process management. International Journal of Information Management. v.33, p.170-193, 2006. 